\title{
Incidence of Salivary gland stone as a main cause of sialoadenitis a clinical study was done on a sample of 22 Iraqi patients
}

\author{
Sahar Abdualkader Ismaeel (1), Wethaq Mohammed Abaas ${ }^{(2)}$ \\ (1) Lecturer, Department of Oral and Maxillofacial Surgery, College of Dentistry, University of Baghdad. \\ (2) Chief Senior of Oral Surgery, AlMaghrib Center of Dentistry
}

\begin{abstract}
Background: sialolithiasis remains an entity carrying a significant morbidity. This study covers the current principles guiding the surgical management of sialolithiasis in Iraqi sample including diagnostic tools, interventional options, surgical techniques and their outcomes.

Materials and Methods: A clinical study of 22 cases with salivary gland stones were collected from two major teaching and referral hospital in Baghdad "Medical city, hospital of surgical specialities" and "Al-Kinidy hospital, maxillofacial department" from 20102015

Results: The study population composed of 22 cases. The age range was from 10-70 year with average of 40 years.

The females were 7 cases (31.81\%) and males were15 (68.18\%). The majority of cases were submandibular gland 16 cases (72.72\%) followed by sublingual gland 5 cases $(22.72 \%)$ and the parotid gland $(4.54 \%)$. The presence of stone was similar on both sides. The surgical approach was applied by removal of stone in 11 cases and removal of gland in 11 cases.

Conclusion: Salivary calculi are common cause of salivary gland disorder. Sialography is an important tool for assessment of salivary gland obstruction in patients presenting with It should be done after the acute symptoms are subsided. Success is measured by treatment that is efficient, clinically effective and glad sparing.
\end{abstract}

\section{INTRODUCTION}

Salivary calculi arise as one or more calcified crystals within ductal system. The development of salivary stones, also known as sialoliths, can cause partially or totally obstruction in the salivary ductal system leading to pain, recurrent brandial swelling of the salivary glands, and acute or chronic infection. The incidence of salivary calculi is predictable between 1 per 15,000 and 1 per 30,000 individuals annualy ${ }^{(1)}$. Salivary stones occur most often in older patients and rarely in children ${ }^{(2)}$. Many studies evident predominancey of males . However, current studies have shown an equal distribution between males and females ${ }^{(3-10)}$. Salivary stones are more found in the submandibular or accessory salivary glands ${ }^{(5,6,9-11)}$ The higher occurrence of salivary stones in the ductal system of the submandibular gland might be due to its longer tortuous duct, salivary flow against gravity, and more alkaline saliva with a higher calcium and mucin content ${ }^{(9)}$. The reason of salivary stone construction remains unclear. However, there are two main theories that explain the formation of salivary stones. The first theory proposes that a local inflammatory process leads to calcification of a mucus plug. The second theory proposes that microsialoliths produced by autophagosomes in the salivary gland, form a nidus for calcium precipitation ${ }^{(2)}$. Salivary caliculi are mainly consisted of inorganic material, such as hydroxyapatite, carbonate apatite, whitlockite, and brushite, with smaller amounts of organic material, such as collagen, glycoproteins,lipids, and carbohydrates ${ }^{(8)}$.Sialography (old gold standered technique) used in chronic cases of sailoadenitis ,provides clear image of stones and the ductal morphologic structures and provide images that are diagnostic for certain conditions, such as Sjogren disease ${ }^{(12)}$.

\section{MATERIALS AND METHODS}

A clinical study analysis of 22 cases with salivary gland stone were collected from two major teaching and referral hospital in Baghdad "Medical city, hospital of surgical specialities" from 20102015.

The collected data obtained from out patient clinic, surgical ward and operative theater of maxillofacial department.

A case sheet form utilized according to age, gender, the salivary gland involved and the side of that gland, and surgical approach.

All informations about the cases were obtained from patient file, case sheet, operative notes .the table below describe the collecting data:- 
Table :

1 number of cases

\begin{tabular}{|c|c|c|c|c|}
\hline $\begin{array}{l}\text { number } \\
\text { of cases }\end{array}$ & age & gender & Types of the lesion & surgical approach \\
\hline 1 & 43 & Male & left submandibular gland stone & surgical removal of the whole gland \\
\hline 2 & 40 & Male & left submandibular gland stone & surgical removal of the stone \\
\hline 3 & 45 & Male & right submandibular gland stone & surgical removal of the whole gland \\
\hline 4 & 39 & Male & left submandibular gland stone & surgical removal of the whole gland \\
\hline 5 & 45 & Male & left submandibular gland stone & surgical removal of the whole gland \\
\hline 6 & 35 & female & right submandibular gland stone & surgical removal of the whole gland \\
\hline 7 & 60 & Male & left submandibular gland stone & surgical removal of the stone \\
\hline 8 & 32 & Male & right submandibular gland stone & surgical removal of the whole gland \\
\hline 9 & 25 & Male & right submandibular gland stone & surgical removal of the whole gland \\
\hline 10 & 45 & Male & left submandibular gland stone & surgical removal of the whole gland \\
\hline 11 & 47 & Male & right submandibular gland stone & surgical removal of the stone \\
\hline 12 & $\mathbf{7 0}$ & Male & right submandibular gland stone & surgical removal of the stone \\
\hline 13 & 45 & female & right sublingual gland stone & surgical removal of the stone \\
\hline 14 & 30 & female & right sublingual gland stone & surgical removal of the stone \\
\hline 15 & 14 & female & left sublingual gland stone & surgical removal of the stone \\
\hline 16 & 34 & female & left submandibular gland stone & surgical removal of the stone \\
\hline 17 & 30 & female & left sublingual gland stone & surgical removal of the stone \\
\hline 18 & 34 & Male & left sublingual gland stone & surgical removal of the stone \\
\hline 19 & 40 & Male & right submandibular gland stone & surgical removal of the whole gland \\
\hline 20 & 10 & Male & left submandibular gland stone & surgical removal of the whole gland \\
\hline 21 & 25 & female & right submandibular gland stone & surgical removal of the stone \\
\hline 22 & 10 & Male & left parotid gland stone & surgical removal of the stone \\
\hline
\end{tabular}

\section{RESULTS}

The study population composed of 22 cases. The age range was from 10-70 year with average of 40 years and majority of cases occur during the third and forth decades of life as showen in the table below. 


\begin{tabular}{|c|c|c|c|c|}
\hline $\begin{array}{c}\text { Age } \\
\text { group }\end{array}$ & Males & Females & Total & $\%$ \\
\hline $\mathbf{1 0 - 2 0}$ & $\mathbf{2}$ & $\mathbf{1}$ & $\mathbf{3}$ & $\mathbf{1 3 . 6}$ \\
\hline $\mathbf{2 0 - 3 0}$ & $\mathbf{1}$ & $\mathbf{3}$ & $\mathbf{4}$ & $\mathbf{1 8 . 1 8}$ \\
\hline $\mathbf{3 0 - 4 0}$ & $\mathbf{5}$ & $\mathbf{2}$ & $\mathbf{7}$ & $\mathbf{3 1 . 1 8}$ \\
\hline $\mathbf{4 0 - 5 0}$ & $\mathbf{5}$ & $\mathbf{1}$ & $\mathbf{6}$ & $\mathbf{2 7 . 2 7}$ \\
\hline $\mathbf{5 0 - 7 0}$ & $\mathbf{2}$ & $\mathbf{0}$ & $\mathbf{2}$ & $\mathbf{9 . 0 9}$ \\
\hline Total & 15 & $\mathbf{7}$ & $\mathbf{2 2}$ & \\
\hline
\end{tabular}

The females were 7 cases $(31.81 \%)$ and males were $15(68.18 \%)$. The majority of cases were submandibular gland 16 cases $(72 \%)$ followed by sublingual gland 5 cases $(22 \%)$ and the parotid gland one case $(6 \%)$. The presence of stone was similar on both sides. The surgical approach was applied by removal of stone in 11 cases and removal of gland in 11 cases.

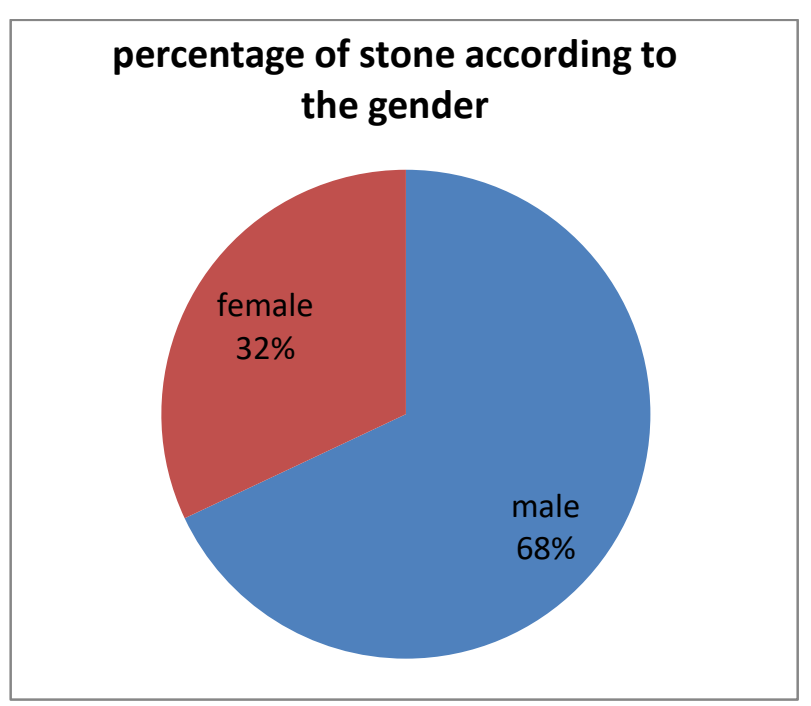

\section{DISCUSSION}

Salivary gland diseases are relatively common. The most frequent non-neoplastic salivary disorder is obstructive sialadenitis, which may be due to calculi, fibromucinous plugs, duct stenosis, foreign bodies, anatomic variations, or malformationof the duct system leading to a mechanical obstruction associated with stasis.

Sialolithiasis is the main cause of obstructive salivary diseases. Sialolithiasis is more frequent in male patients (68.18\%) which are similar to Phillips J, 2014

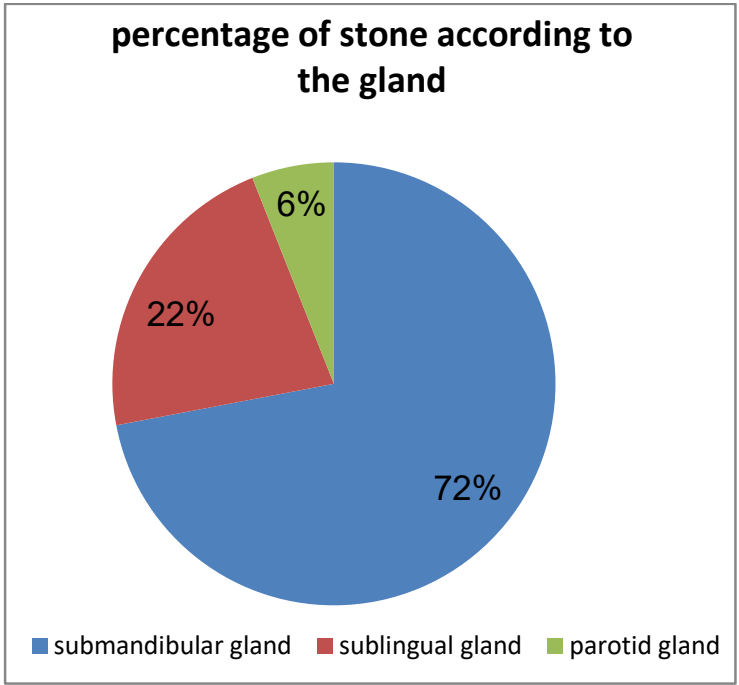

study ${ }^{(6)}$. Incidence peaks between the age of 30 and 60 years which is ahigh range group ,that's why it has no age predilection this is in agree with Lustman J, Regev E and Melamed Y,1990 study ${ }^{(14)}$. It is uncommon in childern Nahlieli O etal $2000^{(15)}$ presented only $9 \%$ of all sialolithiasis cases occur in the population .

Sialolithiasis affects submandibular gland in $72 \%$ of cases, mainly unilatelly but without a preferred side which agree with Stimec etal $2006^{(16)}$ which was party explained by post-mortem morphomertic studies which found a symmetry between the right and left gland. About $4 \%$ of cases occur in the parotid gland. The striking difference between parotid and 
submandibular stones is partially related to the ascendent and sharper angled duct system of the submandibular gland and the type of (mainly mucous) secretion. The sublingual and other minor salivary glands are unexpectedly affected $22 \%$ of cases. In

\section{REFRENCES}

1. Wilson KF, Meier JD, Ward PD. Salivary gland disorders. Am Fam Physician. 2014 Jun 1;89(11):882-.

2. Strychowsky JE, Sommer DD, Gupta MK, Cohen N, Nahlieli O. Sialendoscopy for the management of obstructive salivary gland disease: a systematic review and meta-analysis. Archives of Otolaryngology-Head \& Neck Surgery. 2012 Jun 1;138(6):541-7.

3. Chuangqi Y, Chi Y, Lingyan Z. Sialendoscopic findings in patients with obstructive sialadenitis: long-term experience. British Journal of Oral and Maxillofacial Surgery. 2013 Jun 1;51(4):337-41.

4. Maresh A, Kutler DI, Kacker A. Sialoendoscopy in the diagnosis and management of obstructive sialadenitis. The Laryngoscope. 2011 Mar;121(3):495-500.

5. Serbetci E, Sengor GA. Sialendoscopy: experience with the first 60 glands in Turkey and a literature review. Annals of Otology, Rhinology \& Laryngology. 2010 Mar;119(3):15564.

6Phillips J, Withrow K. Outcomes of holmium laser-assisted lithotripsy with sialendoscopy in treatment of sialolithiasis. Otolaryngology-Head and Neck Surgery. 2014 Jun;150(6):962-7.

7. Terraz S, Poletti PA, Dulguerov P, Dfouni N, Becker CD, Marchal F, Becker M. How reliable is sonography in the assessment of sialolithiasis?. American Journal of Roentgenology. 2013 Jul;201(1):W104-9.

8. Ramakrishna J, Strychowsky J, Gupta M, Sommer DD. Sialendoscopy for the management of juvenile recurrent parotitis: A systematic review and meta-analysis. The Laryngoscope. 2015 Jun;125(6):1472-9.

9. Carlson ER, Ord RA. Benign pediatric salivary gland lesions. Oral and Maxillofacial Surgery Clinics. 2016 Feb 1;28(1):6781.

10Titsinides S, Kalyvas D, Tosios K. Mucocele of the dorsal surface of the tongue: A case report. Journal of clinical and experimental dentistry. 2018 May;10(5):e495.

11. Kraaij S, Karagozoglu KH, Forouzanfar T, Veerman ECI,Brand HS. Salivary stones: symptoms, aetiology, biochemical composition and treatment. $\mathrm{Br}$ Dent $\mathrm{J}$. 2014;217:E23.

12Kiringoda R, Eisele DW, Chang JL. A comparison of parotid imaging characteristics and sialendoscopic findings in obstructive salivary disorders. The Laryngoscope. 2014 Dec;124(12):2696-701.

13Erkul E, Gillespie MB. Sialendoscopy for non-stone disorders: The current evidence. Laryngoscope investigative otolaryngology. 2016 Oct;1(5):140-5.

14.Goncalves M, Mantsopoulos K, Schapher M, Iro H, Koch M. Ultrasound supplemented by sialendoscopy: diagnostic value
Bodner L1993 ${ }^{(17)}$ study the sublingual gland is rarely affected (about 0-5 of cases). Sialolithiasis still represent the most frequent reason for submandibular gland removal.

in sialolithiasis. Otolaryngology-Head and Neck Surgery. 2018 Sep;159(3):449-55.

15.Nahlieli O, Eliav E,Hasson O, Zagury A, Baruchim A.Pediatrric sialolithiiasis.Oral Surg Oral Med Oral pathol 2000;90:709-12.

16.Koch M, Iro H. Salivary duct stenosis: diagnosis and treatment. Acta otorhinolaryngologica italica. 2017 Apr;37(2):132.

17. Aubin-Pouliot A, Delagnes EA, Chang JL, Ryan WR. Sialendoscopy-assisted surgery and the chronic obstructive sialadenitis symptoms questionnaire: A prospective study. The Laryngoscope. 2016 Jun;126(6):1343-8. 